Message from the Editor

\title{
The 'burden of evidence'
}

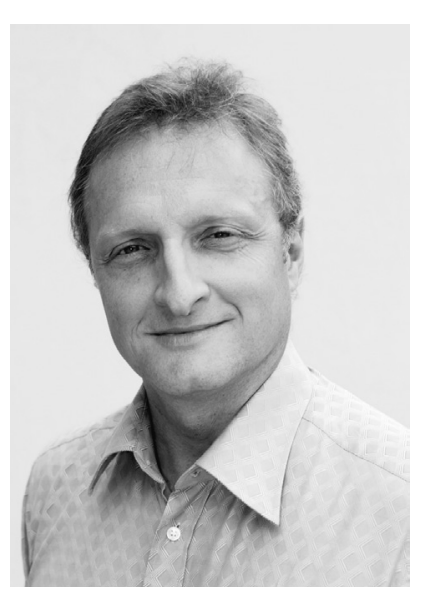

Jens Chapman, MD
The occasion of concluding our first year of EBSJ operations with our third planned issue is a suitable time for reflection on our progress. Firstly, due appreciation to AOSpine and the AO Foundation is in order. Both organizations have unfailingly supported our mission of transforming Evidence Based Spine Surgery, a periodical that produced clinical reviews produced by anonymous contributors, into a credible scientific spine periodical with the specific goal to enhance clinical sciences in the practice of spine care throughout our global multidisciplinary AOSpine care community, through a number of unique features. This is a significant investment of time and money; it is unparalleled in the cut-throat publishing world and would be inconceivable without the support of these one-of-a-kind organizations.

We want to thank you, our readers, for your support, provided in form of contributions, timely quality reviews and many commentaries and suggestions. Overall, the echo we have received has been quite favorable, with particular praise given to our indepth systematic reviews based upon inquiries by AOSpine members with their direct participation. We have also added an editorial staff perspective created from reviewers and editor's comments to scientific articles, and the 'Science in spine' series, which attempts to elevate the general level of scientific understanding throughout our readership from ground level up.

Being a new journal, we are having some challenges with getting enough submissions; which is the single most critical point as the journal lives off quality submissions. It has been suggested that our title of 'Evidence based spine-care journal' is a deterrent to possible authors due to the high expectations inherent to the use of the term 'evidence'. As this is a very crucial point, allow me to reflect on the use of the term evidence in medicine in general and our journal specifically.

\section{What is evidence?}

In its broadest sense, evidence "includes everything that is used to determine or demonstrate the truth of an assertion" according to Wikipedia. From this perspective, there is value in considering all study designs, from the smallest case series to the grandest retrospective cohort study (RCT) and everything in between. All study designs have strengths and limitations and all have the potential to make a meaningful contribution to the overall evidence base on a given topic. What this means is that we are by no means limited to level 1 evidence in the form of RTCs. We hope to inspire the power of observation in our readership in our everyday pursuit of making spine care better for the next patient. This can, for instance, take the form of comparing lumbar lordosis with different spinal frames using simple x-rays (N. Chutkan et al, EBSJ Vol. 1: Issue 1), or can look at reliability of classification systems in spine fracture assessment (A. Stone, EBSJ Vol. 1: Issue 3). None of these studies required high tech, large databases or were contingent upon major statistical calculations. In fact they were all borne out of simple but clinically relevant questions by their authors, and were carried forward to completion with relatively modest means. 
Counter to most other journals we will also provide concrete methodological help to improve a worthwhile project, rather than taking the simple road of outright rejection. With this approach we bring our educational opportunities to you, our readers, and our submitting authors. To this end this edition of EBSJ will feature our first 'enhanced methodological support program (EMSP)', with which our methodology staff supported refinements to a worthwhile study proposal on comparison of laminoplasty results from Beijing, PR China.

\section{Your opinion counts!}

The EBSJ editorial board hopes that you will find reading about the 'evidence in spine care' in the 3rd edition of our Journal thought provoking and insightful. We also hope that you will share our opinion that the term 'evidence' need not be an unattainable obstacle or even a deterrent, but should be an invitation to observe, reflect and report in all ways big and little for all of us practicing spine care. We very much hope to hear from you in two ways:

1. Send us your articles for submissions!

For details go to www.aospine.org/ebsj.

2. Participate in our reader survey.

Please follow this link to the survey: www.surveymonkey.com/s/EBSJsurvey.

We look forward to receiving numerous responses in both categories from our more than 5,000 readers worldwide. And please do join us in our collective journey through the ever evolving evidence base of spinal care! 